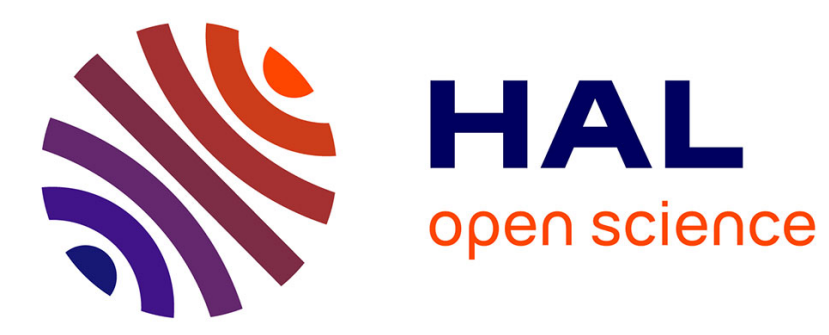

\title{
A Modular High-Temperature Measurement Set-Up for Semiconductor Device Characterization
}

\author{
P. Borthen, G. Wachutka
}

\section{To cite this version:}

P. Borthen, G. Wachutka. A Modular High-Temperature Measurement Set-Up for Semiconductor Device Characterization. THERMINIC 2007, Sep 2007, Budapest, Hungary. pp.189-194. hal-00202559

\section{HAL Id: hal-00202559 \\ https://hal.science/hal-00202559}

Submitted on 7 Jan 2008

HAL is a multi-disciplinary open access archive for the deposit and dissemination of scientific research documents, whether they are published or not. The documents may come from teaching and research institutions in France or abroad, or from public or private research centers.
L'archive ouverte pluridisciplinaire HAL, est destinée au dépôt et à la diffusion de documents scientifiques de niveau recherche, publiés ou non, émanant des établissements d'enseignement et de recherche français ou étrangers, des laboratoires publics ou privés. 


\title{
A Modular High Temperature Measurement Set-Up for Semiconductor Device Characterization
}

\author{
Peter Borthen and Gerhard Wachutka \\ Institute for Physics of Electrotechnology, Munich University of Technology, \\ 80290 München, Germany
}

\begin{abstract}
We demonstrate the capabilities of a high temperature measurement set-up recently developed at our institute. It is dedicated to the characterization of semiconductor devices and test structures in the temperature range from room temperature up to $500^{\circ} \mathrm{C}$ and higher. A detailed description of the experimental equipment is given. Its practical use is demonstrated by measuring temperature-dependent characteristics of silicon VDMOSFET and IGBT devices as well as SiC-diodes. For the silicon devices, numerical simulations based on recently developed high temperature physical models were also performed in order to gain a deeper understanding of the measured data, together with a revalidation of the model parameters.
\end{abstract}

\section{INTRODUCTION}

Electronic devices and modules are increasingly employed in very hot environments such as combustion engines, car brake systems, turbines or well drilling. Therefore, the high temperature characterization of semiconductor devices is getting more and more practical relevance. However, since commercial probe stations do usually not allow for measurements at very high temperatures, semiconductor devices developed to operate in this temperature range cannot be properly characterized using standard equipment. Up to now, only little experimental equipment suited for the electrothermal analysis of semiconductor devices at very high temperatures has been reported. Reggiani at al. $[1,2]$ used a modified commercial high temperature oven for measurements on samples at temperatures as high as $800^{\circ} \mathrm{C}$. $\mathrm{RF}$ measurements on wafers at temperatures up to $500^{\circ} \mathrm{C}$ were described in [3].

With continuously decreasing size and increasing complexity of semiconductor devices, device simulations play an essential role for their optimal design. Device simulations strongly rely on the quality of the physical models implemented in the applied software. This is particularly true for the simulation of high temperature device properties. Till lately, there were no validated models available for temperatures above $250^{\circ} \mathrm{C}$ [4]. Only in recent work the temperature range for calibrated models has been extended to about $400^{\circ} \mathrm{C}$ for the mobility models and even $800^{\circ} \mathrm{C}$ for the impact ionization coefficients $[1,2,5]$. We used these new models for the simulation of the high temperature device behavior described below.

This work was founded by the Dr. Johannes Heidenhain-Stiftung $\mathrm{GmbH}$ and the BMBF under contract $01 \mathrm{M} 3079 \mathrm{E}$.
In the following we describe a versatile, dedicated experimental set-up for the electrical and thermal characterization of semiconductor devices and test structures. The measurements are performed under high vacuum conditions which provides an excellent thermal isolation of the device under test and, at the same time, prevents the degradation of then sample and the system parts due to the exposure to the oxygen in the surrounding air. Apart from measuring device terminal characteristics, the extraction of material properties like carrier mobilities, generationrecombination rates, impact ionization rates, thermal conductivity and others may be performed. The results will be used in the refinement and calibration of physical device models required for the simulation of the high temperature device behavior.

\section{EXPERIMENTAL SET-UP}

A schematic view of the experimental set-up is shown in Fig. 1. It consists of two main building blocks: A vacuum system and a set of measuring instruments controlled by a computer. The vacuum system comprises Trinos modular vacuum chambers [6] with an inner diameter of $40 \mathrm{~cm}$ and a Leybold PT 151 pumping unit [7] consisting of a rotary pump and a turbomolecular pump (Fig. 2). The lower one of the two chambers has several ports for electrical feedthroughs as well as a feedthrough for the cooling liquid.

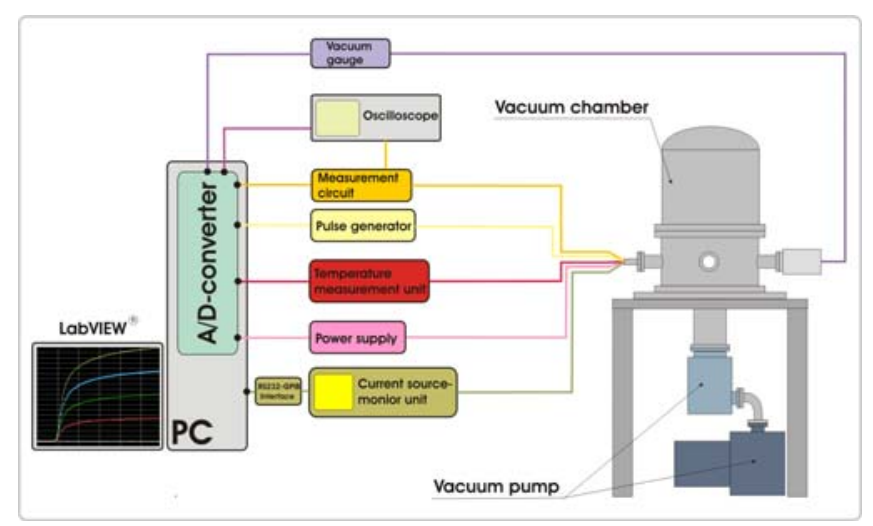

Figure 1. Block diagram of the high-temperature measurement set-up. 


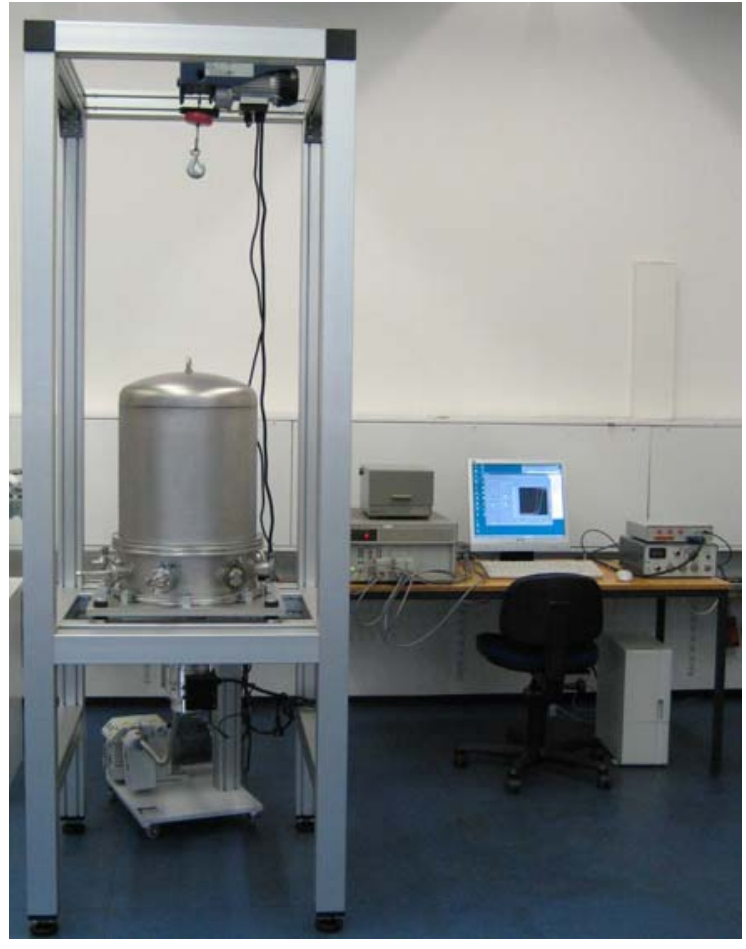

Figure 2. View of the vacuum system.

The chamber bell can be lifted by means of a motorized winch, thus facilitating the access to the measuring platform inside the vacuum chamber. The minimum achievable pressure in the vacuum chamber is about $1 \mathrm{mPa}$ which is limited by the kind of the flanges used in our system (KFflanges) as well as the size of the vacuum chambers and the pumps. However, this pressure is fully sufficient for the purpose of this system. The pumping station can alternatively be connected to the vacuum chamber of a second module for Hall measurement.

Inside the vacuum chamber, different exchangeable measuring platforms can be used depending on the kind of the measurement task. Currently, a general-purpose prober unit (Fig. 3) and a platform with a circuit for high current pulsed measurements (Fig. 4 and 5) are in use. Both systems are inhouse developments.

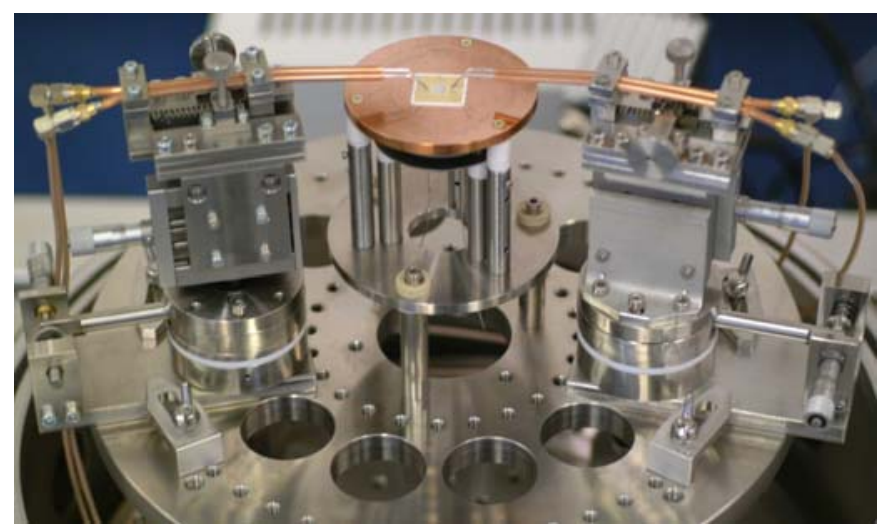

Figure 3. High-temperature sample prober

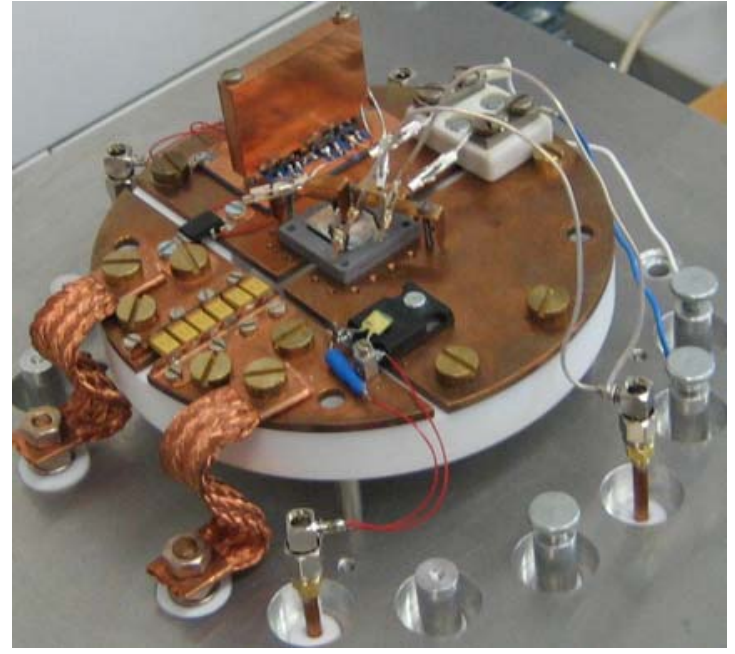

Figure 4. High-temperature circuit for pulsed measurements

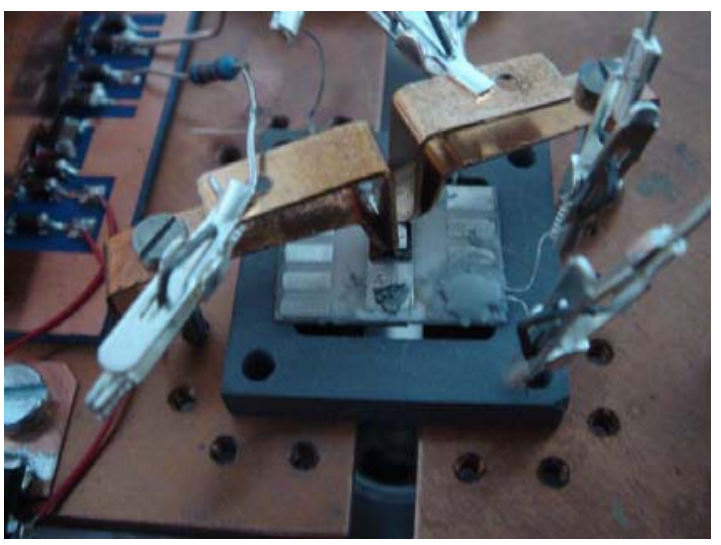

Figure 5. Detailed view of the sample ceramic substrate with electrical contacts. The heating coil is located below the substrate.

The sample stage of the general-purpose prober unit is made of a circular copper plate with a resistive heating coil underneath. With this unit, a maximum temperature of about $600{ }^{\circ} \mathrm{C}$ can be reached. For temperature measurement a PT100 platinum resistor gauge is used which is placed in the vicinity of the sample. Stainless steel manipulators with coax-cable (RG402) cantilevers fixed on top of the manipulators are used for contacting the samples. On one end of the cable (about 6 $\mathrm{mm}$ ) the shielding and the PTFE-dielectric has been removed and the core (silver-plated steel, diameter $0.9 \mathrm{~mm}$ ) has been sharpened to form a probe tip with a radius of approx. $100 \mu \mathrm{m}$. A temperature control and power supply circuit reads and converts the PT100 resistance values. All data is collected by a PC using a PCI-6014 A/D-converter (National Instruments). The whole heating system is controlled by a LabVIEW ${ }^{\circledR}$ program developed for the specific measurement requirements. Currently, another platform is being developed, on which by the use of an electron beam heater measurements up to temperatures of $800-1000^{\circ} \mathrm{C}$ will be achieved.

The electrical characterization of the samples is performed using an Agilent E5270B modular parameter analyzer. It is connected to the $\mathrm{PC}$ via an RS232/GPB-interface and controlled by LabVIEW ${ }^{\circledR}$ software. 


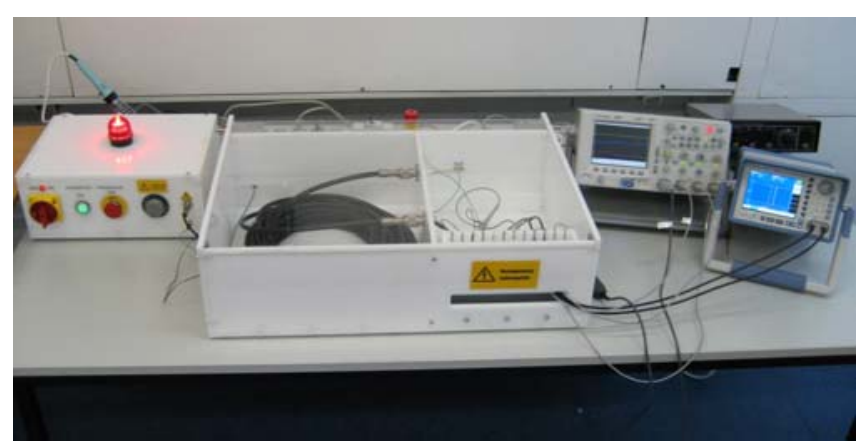

Figure 6. Experimental TLP-System

A number of different measurement modes such as staircase sweep or pulsed measurement can be selected for current-voltage characteristics. The E5270B parameter analyzer is very well suited for measurements in the low and very low current and voltage range. The maximum current in our present instrumental configuration is limited to $1.5 \mathrm{~A}$ and the shortest pulse length possible is $500 \mu \mathrm{s}$.

With a view to extending the capabilities of our set-up to transient recording and higher terminal currents, as it is required for the analysis of power devices, a dedicated electronic circuitry had to be developed. Currently this circuit is able to generate current pulses of max. 200A and pulse lengths between $2 \mu \mathrm{s}$ and $100 \mu \mathrm{s}$. The resistive heating coil is attached to the backside of the ceramic substrate holding the device under test by means of a two-component ceramic adhesive (Fig. 4 and 5).

For high-temperature analysis with very short pulses in the range of $10-500 \mathrm{~ns}$ and voltage amplitudes up to several kilovolts a TLP-System is currently under development. Figure 6 shows an experimental version of the TLP-System used for exploratory tests [8]. This system will enable the investigation of breakdown phenomena in electronic devices under extreme temperature conditions.

\section{DIE-BONDING}

The stability and robustness of the die attachment and the wire bonds is the crucial point for measurements at very high temperature. In order to achieve stable measurement conditions even for temperatures above $700 \mathrm{~K}$, a special die bonding technique (described as NTV process in [9]) is employed. With this process, a very reliable bonding is achieved by applying high mechanical pressure on a porous silver foil placed between the die backside and the metallized substrate at elevated temperature (Fig. 7). The result is a thin sintered layer between die and substrate with excellent bonding properties over a wide range of temperature. Due to the very good electrical and thermal conductivity of silver, its high melting temperature and a well-adapted coefficient of thermal expansion, this bonding method seems to be the best choice for high-temperature test samples.

A relatively high pressure of about $4 \times 10^{7} \mathrm{~Pa}$ and heating above $200^{\circ} \mathrm{C}$ was applied in the original work [9]. As a suitable press for such high mechanical pressure was not available to us, we developed a simple manual press which can be inserted into an oven for the heating step.
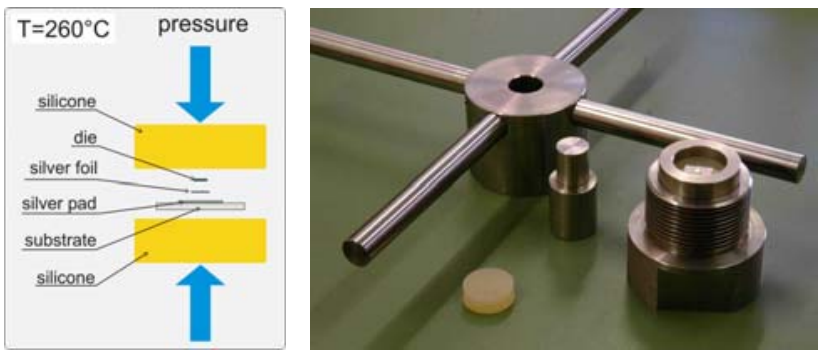

Figure 7. Principle of the NTV die bonding technique (left) and a simple manual press developed in-house (right), which allows for die bonding on substrates as large as $22 \times 22 \mathrm{~mm}^{2}$.

The maximum pressure achieved with this press was estimated to be about $1 \times 10^{7} \mathrm{~Pa}$. As this value is lower compared to that in [9], we had to raise the sintering temperature to about $260^{\circ} \mathrm{C}$ and extend the pressing time to about $1 \mathrm{~h}$ in order to achieve comparable results. All samples bonded by this method proved to be mechanically and electrically very stable: There were no signs of failure even after repeated heating up to $500^{\circ} \mathrm{C}$.

\section{High-TEMPERATURE MEASUREMENT AND SimUlation ON TEST DEVICES}

Figure 8 shows the measured and the simulated transfer characteristics, respectively, of a 75V MOSFET placed within a PCM test structure, which had been fabricated by means of the so-called SFET2 process technology available at Infineon. The PCM test structure comprises 38 MOSFET cells only, whereas the full device consists of about 500,000 cells.

As we can recognize from Fig. 8, the basic MOSFET operation stays stable (with negative temperature coefficient) up to a temperature of about $300^{\circ} \mathrm{C}$. Above this temperature level, the drain current increases with temperature so that the device is likely to run into an electrothermal instability leading eventually to device failure. However, already between $200^{\circ} \mathrm{C}$ and $300^{\circ} \mathrm{C}$ we find a significant increase in the subthreshold current and a decrease of the threshold voltage, which is considerably larger than that at lower temperatures. This device degradation is mainly caused by the decreasing electron mobility and the increasing thermal generation of electron-hole pairs observed at rising lattice temperature.

It turns out that the high-temperature simulation models, which should be able to cover the full temperature range of the measured data, still need a recalibration of the model parameters. With the given temperature dependence in the physical models as implemented in DESSIS, it is virtually impossible to find a single parameter set that would perfectly describe the device operation for all temperature values between room temperature and $400^{\circ} \mathrm{C}$. An acceptable agreement between measurement and simulation could only be achieved after re-adjusting the temperature dependence in a number of model parameters. Actually, this re-adjustment had to be made for the parameters of band gap narrowing, channel mobilities, and generation-recombination processes.

The next device type investigated in this work was a $600 \mathrm{~V}$ NPT (non-punch-through) IGBT. Due to their specific structure, IGBTs show a high-temperature behaviour that 


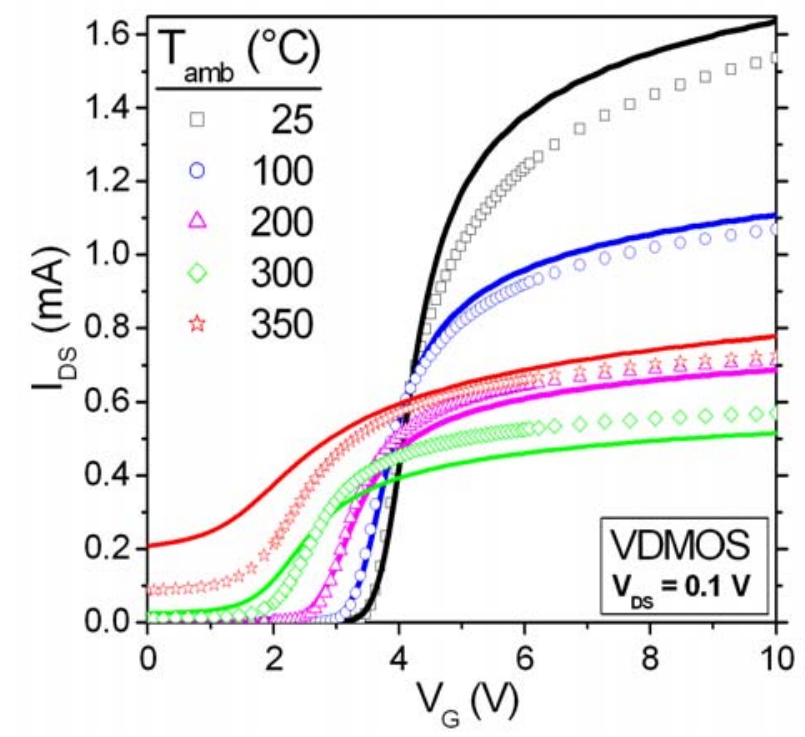

Figure 8. Transfer characteristics of a silicon VDMOSFET test structure. Solid lines: Measurement; Symbols: Simulation.

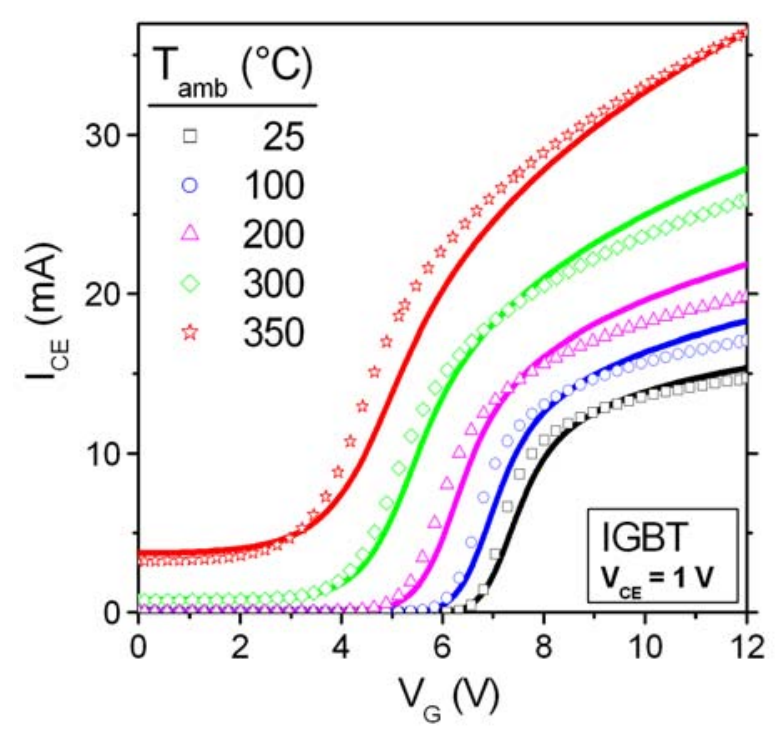

Figure 9. Transfer characteristics of an IGBT-device. Solid lines: Measurement; Symbols: Simulation.

combines that of a MOSFET with that of a BJT. As a result, the forward characteristics exhibit two voltage regions with a positive, BJT-type, and a negative, MOSFET-type temperature coefficient. There exists also one operating point $\left(\mathrm{U}_{\mathrm{CE}}, \mathrm{I}_{\mathrm{CE}}\right)$ in the characteristics which is nearly independent of temperature. Measured and simulated transfer characteristics are shown in Figure 10.

The avalanche breakdown voltage constitutes the maximum voltage a semiconductor device can sustain in the blocking state. It is therefore one of the most important parameters that specifies the safe operating area of the device. For p-n junctions, it is known that the avalanche breakdown voltage increases with increasing temperature due to the lattice scattering rate of the charge carriers. We have measured the static drain-source breakdown voltage for temperatures between room temperature and $400^{\circ} \mathrm{C}$. As shown in Figure 9, the breakdown voltage increases linearly with temperature in the whole temperature range investigated. The corresponding simulations were performed using the traditional mobility model of Masetti et al [10] as well as the new model developed at the University of Bologna. The parameters used in these simulations were the same as those obtained from the quasi-static simulation of the transfer characteristics (i.e. the simulation data shown in Fig. 10 are based on the re-calibrated models rather than the result of a fit). This example suggests the conclusion that the re-calibrated physical models provide a satisfactory description of MOSFET-like devices.

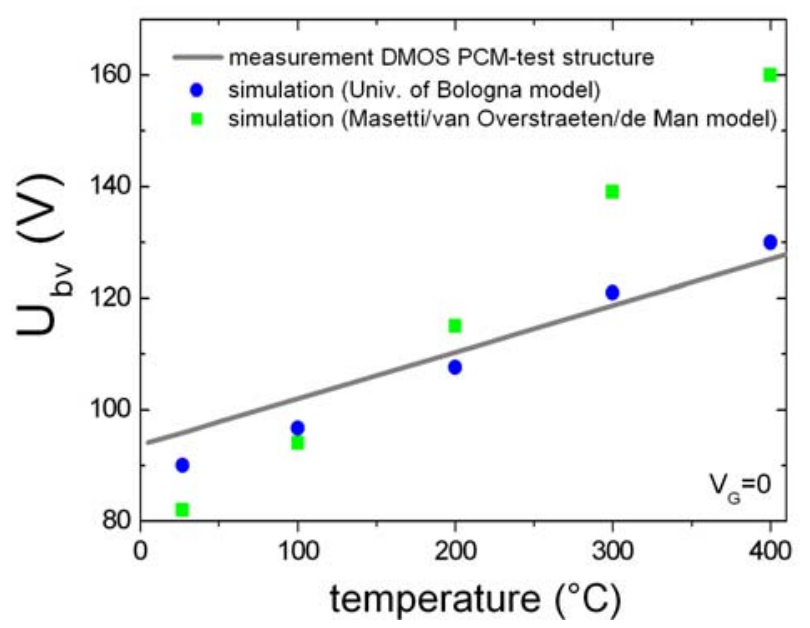

Figure 10. VDMOSFET test structure. Breakdown voltage as a function of temperature. Solid line: measurement; Symbols: simulation.
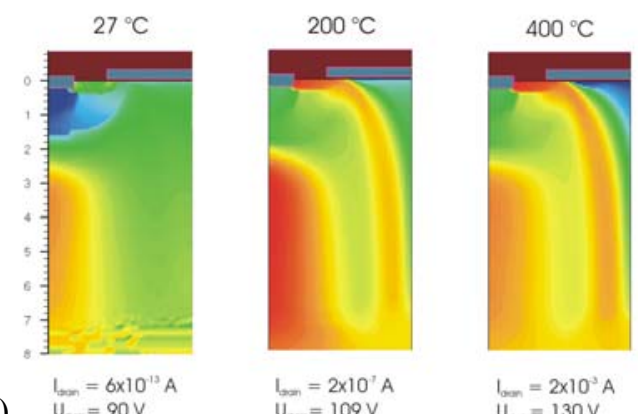

(a)
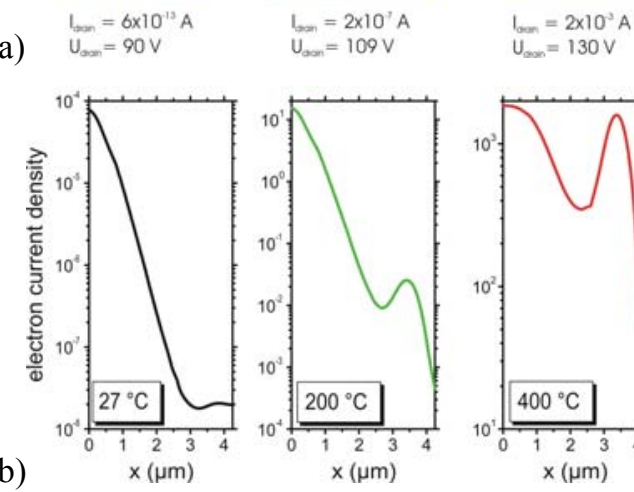

(b)
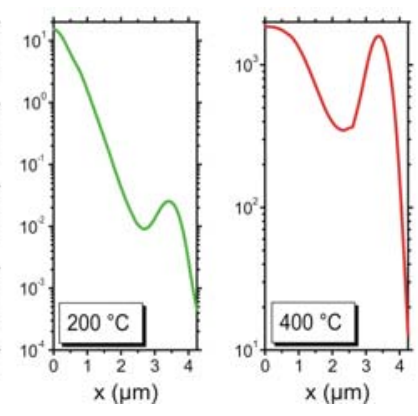

Figure 11. VDMOSFET test structure. a) Simulated electron current density for $\mathrm{U}_{\mathrm{D}}=\mathrm{U}_{\mathrm{BV}}$; b) Simulated electron current density along the $\mathrm{x}$ - coordinate line $\mathrm{y}=3 \mu \mathrm{m}$ in the upper figure. 
More details of the physical process occurring during avalanche breakdown in the interior of these devices are shown in Fig. 11. The distribution of the electron current at the onset of breakdown for temperatures between $27^{\circ} \mathrm{C}$ and $400^{\circ} \mathrm{C}$ are displayed in Figure 11a. It demonstrates the uncontrolled shift of the current path from the body-epilayer diode to the parasitic n-p-n transistor indicating the turn on of the latter at about $200^{\circ} \mathrm{C}$. Figure $11 \mathrm{~b}$ shows the radial electron current distribution at a depth of $3 \mu \mathrm{m}$. It makes evident that at $400^{\circ} \mathrm{C}$ a significant part of the avalanche current flows through the parasitic transistor. These facts are closely related to the findings reported by Icaza-Deckelmann et al. [11] considering the unclamped inductive switching failure of DMOStransistors.

For the device simulations we used a version of the commercial simulation tool DESSIS (formerly ISE-TCAD, now Synopsys) [12], in which these extended high temperature models were available. Table 1 summarizes the physical simulation models used in the present work.

TABLE I

PHYSICAL MODELS USED FOR THE DEVICE SIMULATION

\begin{tabular}{|l|l|c|}
\hline Physical effect & Model used & Reference \\
\hline band gap narrowing & Slotboom & {$[13]$} \\
\hline bulk mobility & Univ. of Bologna & {$[2]$} \\
\hline channel mobility & Lombardi & {$[14]$} \\
\hline carrier-carrier scattering & Brooks/Herring & - \\
\hline high field saturation & Canali & {$[15]$} \\
\hline recombination & SRH, Auger & - \\
\hline avalanche generation & Univ. of Bologna & {$[5]$} \\
\hline
\end{tabular}

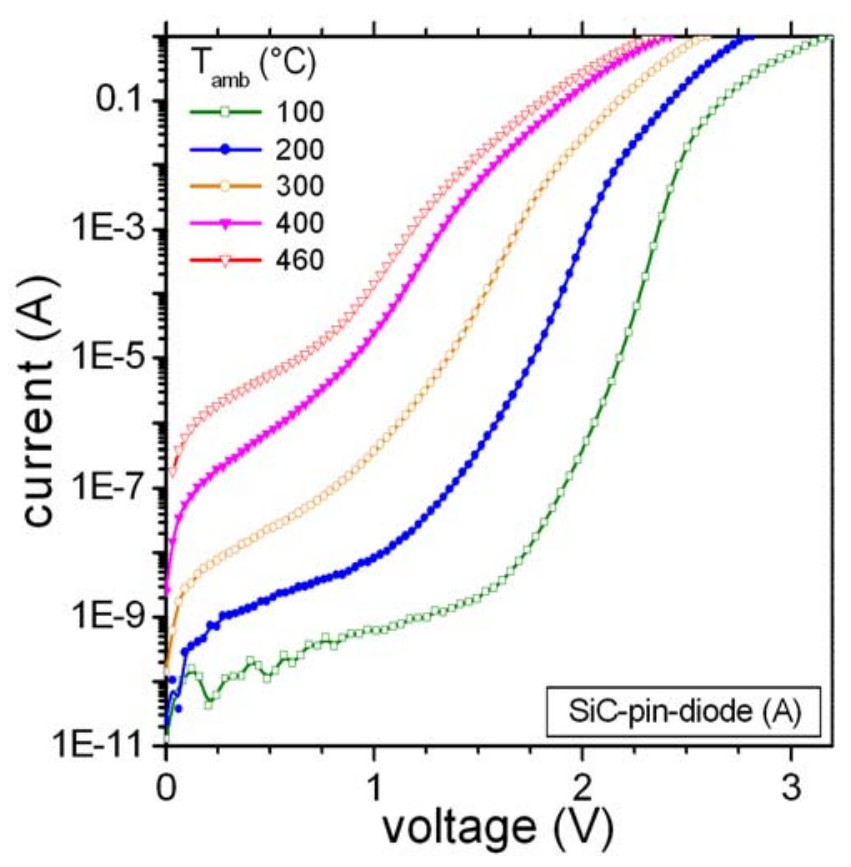

Figure 12. Forward characteristics of a silicon carbide pin-diode for temperatures between $100^{\circ} \mathrm{C}$ and $460^{\circ} \mathrm{C}$.

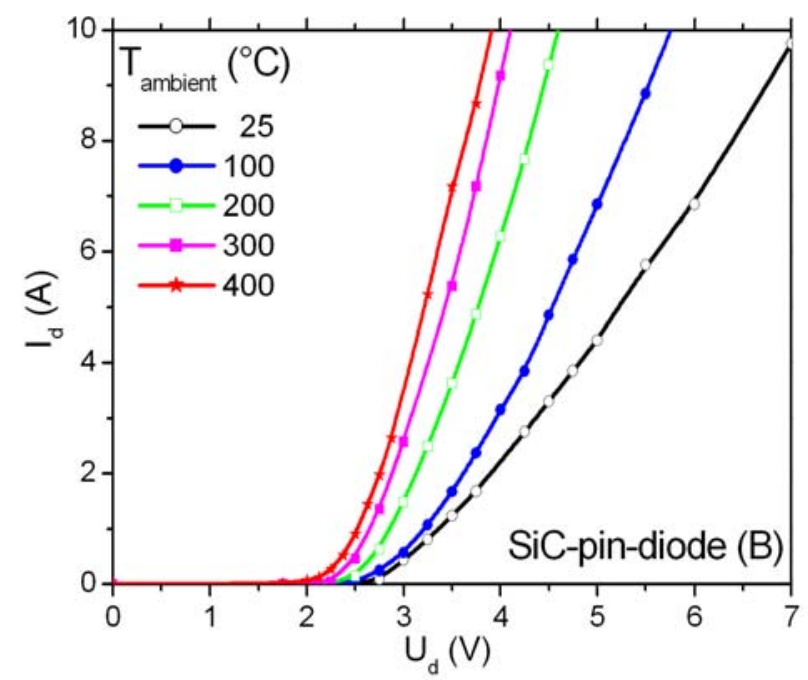

Figure 13. Forward characteristics of another SiC-pin-diode measured with short pulses. The pulse length and period was $100 \mu$ s and $50 \mathrm{~ms}$, respectively.

Results for two $\mathrm{SiC}$ samples, both delivered by SiCED $\mathrm{GmbH}$ (Germany), are shown in figures 12 and 13. Fig. 12 displays the forward characteristics of a $\mathrm{SiC}$ pin diode for temperatures between $25^{\circ} \mathrm{C}$ and $460^{\circ} \mathrm{C}$. The diode can be operated up to about 15 A [16], but the maximum current measured was limited by our parameter analyzer to $1 \mathrm{~A}$. Pulsed measurements up to $400^{\circ} \mathrm{C}$ for another sample of the same SiC-pin diode are shown in Fig. 13. More detailed results for the high-temperature behavior of SiC-pin diode may be found in [17].

\section{ACKNOWLEDGMENTS}

We would like to thank SiCED GmbH for providing the $\mathrm{SiC}$ samples, Infineon for DMOS and IGBT samples and for fruitful collaboration. We also thank $\mathrm{H}$. Schwarzbauer (Siemens AG) for the support with the NTV-method.

\section{REFERENCES}

[1] S. Reggiani et al., "Measurement and modeling of the electron impactionization coefficient in silicon up to very high temperatures," IEEE Trans. on Electron Devices, vol. 52, no. 10, pp. 2290-2296, Oct. 2005.

[2] S. Reggiani et al., "Electron and hole mobility in silicon at large operating temperatures. I. Bulk mobility," IEEE Trans. on Electron Devices, vol. 49, no. 3, pp. 490-499, Mar. 2002.

[3] Z.D. Schwartz, A.N. Downey, S.A. Alterovitz and G.E. Ponchak, "High-temperature RF probe station for device characterization through 500/spl deg/C and $50 \mathrm{GHz}$," IEEE Trans. on Instrumentation and Measurements, vol. 54, no. 1, pp. 369-375, Feb. 2005.

[4] A. Schenk, "Advanced physical models for silicon device simulation", Springer Verlag, Wien, 1998

[5] S. Reggiani, M Valdinoci, L. Colalongo and G. Baccarani, "A unified analytical model for bulk and surface mobility in Si n- and p-channel mosfets", ESSDERC 1999 Proceedings, pp. 240-243, 1999

[6] Trinos, www. trinos.com

[7] Oerlikon.-Leybold, www.oerlikon.com

[8] Yuan Liu, "Simulation, Tests und Optimierung eines Kabelpulsers", Diploma thesis, TU München, April 2007

[9] H. Schwarzbauer and R. Kuhnert, "Novel large area joining technique for improved power device performance," IEEE Trans. on Ind. Appl., vol. 27, no. 1, pp. 93-95, Jan./Feb. 1991. 
[10] G. Masetti, M. Severi and S. Solmi, "Modelling od carrier mobility against carrier concentration in Arsenic-, Phosphorus- and Boron-doped Silicon", IEEE Transactions on Electron Devices, vol. ED-30, 764-769, 1983.

[11] A. Icaza-Deckelmann, G. Wachutka, F. Hirler, J. Krumrey, "UISFailure for DMOS Power Transistors", ESSDERC 2002 Proceedings, pp. 459-462, 2002

[12] Synopsis, www.synopsis.com

[13] J.W. Slotboom, H.C. de Graaf, "Measurements of bandgap narrowing in Si bipolar transistors", Solid-State Electronics, vol. 19, pp. 857-862, 1976

[14] C. Lombardi, S. Manzini, "A physically based mobility model for numerical simulation of nonplanar devices", IEEE Transctions on CAD, vol. 7, no.11, pp. 1164-1171, 1988

[15] C. Canali, G. Majni, R. Minder, G. Ottaviani, "Electron and hole drift velicity and their empirical relation to electric field and temperature", IEEE Transactions on Electron Devices, vol. ED-22, pp. 1045-1047, 1975

[16] W. Bartsch et al., "Bipolar $6.5 \mathrm{kV}-\mathrm{SiC}$-diodes: on the road to industrial application," Proceedings of European Conference on Power Electronics and Applications, Dresden, September, 11th-14th, 2005.

[17] D. Werber, P. Borthen and G. Wachutka, "Behaviour of 4H-SiC pin diodes studied by numerical device simulation," Silicon Carbide and Related Materials 2006, pp. 905-908, Trans Tech Publications Ltd, Zürich. 